\title{
Micronutrients intake in overweight adults with chronic spinal cord injury - result from Spinal Clinic for Obese Outpatient Project (SCOOP)
}

\author{
S. S. Wong ${ }^{1,2}$, A. Graham ${ }^{1}$, T. $\mathrm{Ng}^{1}$, A. Forbes ${ }^{2}$ and G. Grimble ${ }^{2}$ \\ ${ }^{1}$ National Spinal Injuries Centre, Stoke Mandeville Hospital, Aylesbury, UK and ${ }^{2}$ Centre of Gastroenterology and Clinical \\ Nutrition, University College London Hospital, Aylesbury, UK
}

A substantial literature has reported on the prevalence of under- and over-nutrition in selected patient groups; as yet, there is little published evidence of nutrition status of patients with spinal cord injuries (SCI) ${ }^{(1,2)}$. This study makes attempts to compile the micronutrients profile of over-nourished adults living in the UK with SCI and to compare their intake with the Reference Nutrient Intake (RNI) and Lower Reference Nutrient Intake (LRNI) set by the Department of Health ${ }^{(3)}$ and the National Dietary Nutrition Survey (NDNS) ${ }^{(4)}$. Of 22 patients recruited from the weight management clinic, $\left(47.1 \pm 13.4\right.$ years; BMI: $\left.35.5 \mathrm{~kg} / \mathrm{m}^{2}\right)$, this study found patients who are overweight with SCI failed to meet the recommended values set by the UK Department of Health for K (81.8\% of sample), Cu (62\% of sample), Se (100\% of sample), iodine (59\% of sample) and $\mathrm{Ca}, \mathrm{Na}, \mathrm{Fe}$ and $\mathrm{Zn}$ for female patients. The intake of $\mathrm{Ca}$, phosphorus, $\mathrm{Mg}$, $\mathrm{Na}$, $\mathrm{K}, \mathrm{Fe}, \mathrm{Cu}$, thiamine, riboflavin, nicotinic acid, vitamin $\mathrm{B}_{6}$, vitamin $\mathrm{B}_{12}$, folate, vitamin $\mathrm{A}$, vitamin $\mathrm{D}$ and vitamin $\mathrm{E}$ was lower than the findings of the UK national diet and nutrition survey data. This study shows the numbers of micronutrient inadequacies, relative to the RNI, LRNI and NDNS data. In light of excess energy intake leading to weight gain, the presence of nutritional deficiencies in these groups of patients may seem paradoxical. Causes are multifactorial, and probably include decreased consumption of fruits and vegetables, increased intake in sugar and alcohol. Their diets are nutritionally poor-quality food, such as take away, alcohol and fizzy drinks and change in body composition post SCI, which may influence the storage and availability of certain nutrients. As obesity in SCI has reached an epidemic, apart from introducing appropriate interventions to treat obesity, clinicians must also be aware of possible pre-existing nutritional deficiencies in obese patients. Current guidance on nutritional requirement may be insufficient in the SCI population. In order to identify specific health outcomes where the population failed to meet the recommendation and offer area of improvements, further research on nutrient intake in this group of patients, with a larger sample size is warranted.

\begin{tabular}{|c|c|c|c|c|c|c|c|c|}
\hline \multirow[b]{2}{*}{ Nutrient group } & \multicolumn{2}{|c|}{ SCI group (mean) } & \multicolumn{2}{|c|}{ NDNS } & \multicolumn{2}{|r|}{ RNI } & \multicolumn{2}{|r|}{ LRNI } \\
\hline & Men & Women & Men & Women & Men & Women & Men & Women \\
\hline Calcium (mg /d) & 846 & 595.5 & 1007 & 777 & 700 & 700 & 400 & 400 \\
\hline Phosphorus (mg /d) & 1252 & 930.8 & - & - & 550 & 550 & - & - \\
\hline Magnesium (mg/d) & 288.7 & 210.7 & 1493 & 1112 & 200 & 270 & 190 & 150 \\
\hline Sodium $(\mathrm{mg} / \mathrm{d})$ & 2267 & 1525 & 3313 & 2302 & 1600 & 1600 & 575 & 575 \\
\hline Potassium (mg/d) & 2740 & 2234 & 3367 & 2653 & 3500 & 3500 & 2000 & 2000 \\
\hline Iron $(\mathrm{mg} / \mathrm{d})$ & 11.3 & 8.5 & 11.3 & 8.5 & 8.7 & $14.8(19-50) ; 8.7(50+)$ & 4.7 & $8(19-50) ; 4.7(50+)$ \\
\hline Zinc $(\mathrm{mg} / \mathrm{d})$ & 10.8 & 6.4 & 10.2 & 7.4 & 9.5 & 7.0 & 5.5 & 4.0 \\
\hline Copper (mg/d) & 0.98 & 0.74 & 1.43 & 1.03 & 1.2 & 1.2 & - & - \\
\hline Selenium (mg/d) & 33.2 & 21.02 & - & - & 75 & 60 & 40 & 40 \\
\hline Iodine (ug/d) & 113.5 & 113.7 & 215 & 159 & 140 & 140 & 70 & 70 \\
\hline Thiamin $(\mathrm{mg} / \mathrm{d})$ & 1.41 & 1.26 & 2.0 & 1.54 & 1.0 & 0.8 & 0.23 & 0.23 \\
\hline Riboflavin (mg/d) & 1.89 & 1.25 & 2.11 & 1.66 & 1.3 & 1.1 & 0.8 & 0.8 \\
\hline Nicotinic acid (mg/d) & 29.9 & 26.0 & 44.7 & 30.9 & 6.6 & 6.6 & 4.4 & 4.4 \\
\hline Vitamin $B_{6}(\mathrm{mg} / \mathrm{d})$ & 1.79 & 1.49 & 2.9 & 2 & 1.5 & 1.5 & 1.0 & 1.0 \\
\hline Vitamin $B_{12}(\mathrm{ug} / \mathrm{d})$ & 6.3 & 3.8 & 6.5 & 4.8 & 1.5 & 1.5 & 1.0 & 1.0 \\
\hline Folate (ug/d) & 247.8 & 209.4 & 344 & 251 & 200 & 200 & 100 & 100 \\
\hline Vitamin C & 72.5 & 119.4 & 83.4 & 81 & 40 & 40 & 10 & 10 \\
\hline Vitamin A & 714 & 782 & 911 & 671 & 700 & 600 & 300 & 250 \\
\hline Vitamin D & 2.86 & 2.31 & 3.7 & 2.8 & $10(50+)$ & $10(50+)$ & - & - \\
\hline Vitamin E & 5.95 & 4.62 & 6.5 & 3.9 & - & - & & \\
\hline
\end{tabular}

SCI: Spinal cord injury group; NDNS: National Dietary and Nutrition Survey ${ }^{4}$ RNI: Reference Nutrient Intake ${ }^{3}$; LRNI: Lower Reference Intake ${ }^{3}$.

1. Tomey KM, Chen DM, Wang X et al. (2005) Dietary intake and nutritional status of urban community-dwelling men with paraplegia. Arch Phys Med Rehabil 86, 664-671.

2. Walters JL, Buchholz AC \& Martin Glinis KA (2009) Evidence of dietary inadequacy in adults with chronic spinal cord injury. Spinal Cord 47, $318-322$.

3. Department of Health (1991) Dietary Reference Values of Food Energy and Nutrients for the United Kingdom. Report on Health and Social Subjects No. 41. London: H.M. Stationery Office.

4. Henderson L, Gregory J, Irving K et al. (2003) The National Diet and Nutrition Survey: Adults Aged 19-64 Years, Volume 3: Vitamins and Mineral Intake and Urinary Analyses. London: HMSO. 